\title{
Systemic Cell Death Is Elicited by the Interaction of a Single Gene in Nicotiana clevelandii and Gene VI of Cauliflower Mosaic Virus
}

\author{
Lóránt Király, Anthony B. Cole, June E. Bourque, and James E. Schoelz \\ Department of Plant Pathology, University of Missouri, Columbia 65211, U.S.A. \\ Accepted 7 June 1999.
}

Cauliflower mosaic virus (CaMV) strains D4 and W260 can be distinguished by the type of symptoms they induce in Nicotiana clevelandii and $N$. edwardsonii. W260 induces systemic cell death in addition to a mosaic symptom in $N$. clevelandii and a hypersensitive response (HR) in $N$. edwardsonii, whereas D4 induces a systemic mosaic in both hosts. To determine which $\mathrm{W} 260$ genes are responsible for systemic cell death, chimeric viruses were constructed between the D4 and W260 strains. It was found that W260 gene VI was responsible for the elicitation of systemic cell death; previous studies had shown that this same gene elicited HR in $N$. edwardsonii. An immunological analysis of plants infected with W260 or D4 indicated that the systemic cell death symptom was not associated with enhanced levels of either W260 virions or the W260 gene VI product. To investigate the inheritance of systemic cell death, crosses were made between $N$. clevelandii and $N$. bigelovii, a host that reacts with a systemic mosaic symptom upon infection with $\mathbf{W} 260$. All $F_{1}$ plants developed a systemic mosaic after inoculation with W260, whereas the $F_{2}$ generation segregated 3:1 for systemic mosaic versus cell death. The plant gene responsible for cell death was designated $c c d 1$, for $\underline{\mathrm{CaMV}}$ cell death gene. These results demonstrate that the systemic cell death symptom in $N$. clevelandii is induced by the interaction between a single host gene and gene VI of CaMV.

The characteristic symptoms induced by plant viruses are likely the result of specific interactions between virus and plant genes. Over the past several years, genes and noncoding nucleotide sequences of plant DNA viruses, RNA viruses, and satellite viruses have been identified that determine symptom formation and host range (for reviews see Daubert 1988; Culver et al. 1991; Dawson and Hilf 1992). On the host side, it has been shown that plant virus infections can trigger substantial changes in host gene expression (Wang and Maule

Corresponding author: James E. Schoelz; Fax: 1-573-882-0588; E-mail: schoelzj@missouri.edu

Current address of Lóránt Király: Plant Protection Institute, Budapest, Hungary.

Current address of June E. Bourque: Monsanto Agricultural Company, St. Louis, MO 63167, U.S.A
1995; Geri et al. 1999). There are, however, few examples of host genes that interact in a specific manner with virus sequences to produce the characteristic symptoms of a virus infection.

One symptom that is elicited by many plant viruses is systemic cell death. In some cases, the systemic cell death may represent a failure of the host's hypersensitive defense response to stop the spread of the virus. Thus, it has been noted that Nicotiana spp. that contain the $N$ gene may develop systemic cell death in response to infection by tobacco mosaic virus (TMV), even when plants are maintained at 17 to $20^{\circ} \mathrm{C}$ (Dijkstra et al. 1977). Furthermore, single amino acid substitutions within the coat protein of TMV may act as weak elicitors of hypersensitive response (HR) and may actually facilitate systemic cell death in tobacco that contain the $N^{\prime}$ gene (Culver and Dawson 1989). In other cases, the elicitation of systemic cell death by viruses does not appear to be associated with a host resistance gene. For example, both tomato bushy stunt virus and selected satellite RNAs of cucumber mosaic virus (CMV) trigger systemic cell death in their hosts (Scholthof et al. 1995; Taliansky et al. 1998), but this has not been correlated with the failure of any form of host resistance.

In this study, we considered that the interaction of cauliflower mosaic virus (CaMV) with Nicotiana spp. may be one system in which both host and viral determinants of systemic cell death might be identified. CaMV strain W260 elicits systemic cell death in $N$. clevelandii and only a mosaic in $N$. bigelovii whereas CaMV strain D4 elicits mosaic symptoms in both hosts (Fig. 1). As with many plant viruses, it is possible to construct chimeras between different CaMV strains to identify symptom and host range determinants (Daubert et al. 1984; Schoelz et al. 1986a; Stratford and Covey 1989). This approach has been used to show that gene VI of CaMV strain W260 is responsible for elicitation of an HR in N. edwardsonii (Schoelz and Shepherd 1988). On the host side, the interspecific cross between $N$. clevelandii and $N$. bigelovii is fertile, and consequently it has been possible to show that a yellow mosaic symptom induced in $N$. bigelovii by a satellite RNA of CMV is determined by a single, incompletely dominant plant gene (Masuta et al. 1993).

The objective of the present study was to determine the inheritance of both host and virus genes that condition the systemic cell death symptom in $N$. clevelandii. To identify virus sequences specifying systemic mosaic or cell death in $N$. clevelandii, we utilized chimeric viruses constructed 
between the CaMV strains W260, D4, and CM1841. We also generated crosses between $N$. bigelovii and $N$. clevelandii to identify host genes responsible for the systemic mosaic and cell death traits. We present evidence that an interaction between CaMV gene VI and a single $N$. clevelandii gene determines the development of systemic cell death upon viral infection.

\section{RESULTS}

Gene VI of CaMV strain W260 is responsible for the development of systemic cell death in $N$. clevelandii.

CaMV strain D4 causes a systemic mosaic in N. clevelandii (Fig. 2A), whereas CaMV strain W260 induces systemic cell death in addition to the mosaic (Fig. 2B). In a typical test, $N$. clevelandii plants inoculated with W260 initially developed a mixture of chlorotic and necrotic lesions on the inoculated leaves 8 to 10 days post inoculation (dpi), and a systemic mosaic about 20 to $23 \mathrm{dpi}$. A few days after the onset of mosaic symptoms, small necrotic lesions appeared among the mosaic symptoms. These necrotic lesions subsequently became larger and eventually coalesced in the advanced stages of systemic infection. In some cases, entire leaves became necrotized. In contrast, D4-inoculated $N$. clevelandii developed chlorotic lesions and a systemic mosaic; these plants never developed necrotic symptoms.

All W260-inoculated $N$. clevelandii plants developed systemic cell death, but symptom severity was affected by environmental conditions such as light intensity, daylength, and temperature. More severe systemic cell death appeared under conditions of low light intensity, low temperature (18 to $20^{\circ} \mathrm{C}$ ), and short days (9- to 10 -h photoperiod). In tests conducted during the winter months, the conditions favoring systemic cell death were best met by maintaining inoculated plants in the greenhouse. In summer, tests were conducted in growth chambers in order to reproduce winter greenhouse conditions.

To identify regions of the W260 genome that determine systemic cell death in $N$. clevelandii, chimeric viruses were constructed between strains W260 and D4. Previous studies with chimeric CaMV strains have shown that sequences within gene VI can elicit an HR in N. edwardsonii and Datura stramonium (Schoelz et al. 1986a; Schoelz and Shepherd 1988). To test the possibility that gene VI might also elicit systemic cell death in $N$. clevelandii, the entire gene VI coding region was exchanged between W260 and D4 to form the chimeric viruses H190 and H191 (Fig. 1). H191 induced systemic cell death in $N$. clevelandii (Fig. 2C) and HR in N. edwardsonii. In contrast, H190 induced only a systemic mosaic in both $N$. clevelandii (Fig. 2D) and N. edwardsonii. We concluded that sequences within the $3^{\prime}$ end of gene V, gene VI, and/or the large intergenic region were responsible for the elicitation of systemic cell death in $N$. clevelandii, as well as HR in N. edwardsonii.

Two other chimeric viruses, H7 and H35 (Fig. 1), had been used in previous studies to show that gene VI of CaMV strain D4 determines systemic infection of $N$. edwardsonii, and that sequences within the $5^{\prime}$ third of W260 gene VI elicit HR in $N$. edwardsonii (Schoelz and Shepherd 1988). In the present study, we confirmed the reactions of $\mathrm{H} 7$ and $\mathrm{H} 35$ in $N$. edwardsonii, and then used these viruses to investigate whether the $5^{\prime}$ third of W260 gene VI was sufficient to elicit systemic necrosis. We found that $\mathrm{H} 7$ induced a systemic mosaic in $N$. clevelandii, while $\mathrm{H} 35$ induced systemic necrosis in that host (Fig. 1). Thus, the same region of CaMV gene VI responsible for elicitation of HR in N. edwardsonii also could elicit systemic cell death in $N$. clevelandii. It is also significant to note that neither H35 nor H191 induced systemic cell death in $N$. bigelovii, a result that is consistent with the reaction of the parent viruses-W260 and D4—in this host (Fig. 1).

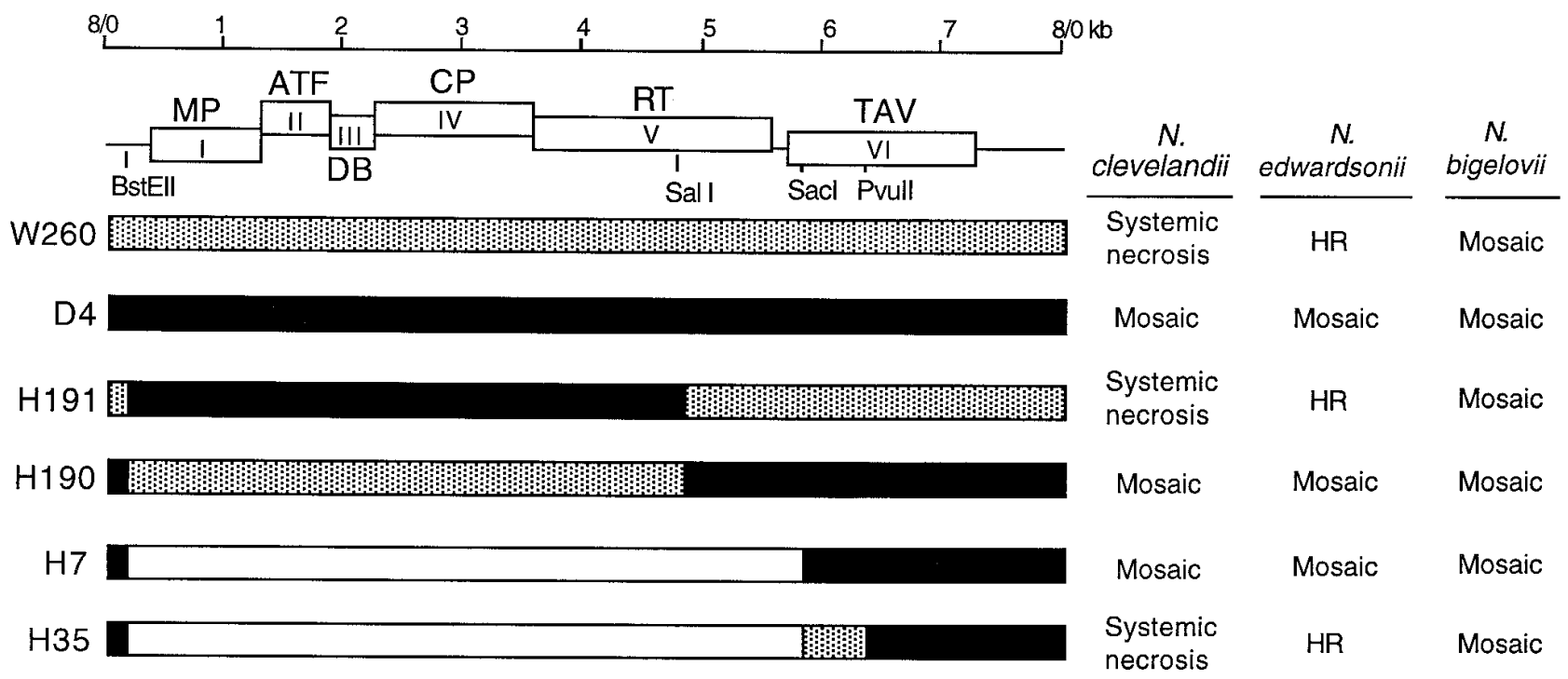

Fig. 1. Composition of the chimeric cauliflower mosaic virus (CaMV) constructed between W260, D4, and CM1841 to identify W260 regions that influence systemic necrosis and hypersensitive response (HR). Viral genomes are drawn in a linear form to facilitate comparisons. Zero nucleotide position corresponds to left end, while the 8031 nucleotide corresponds to right end, of each map. Functions of the six genes: Gene I, cell-to-cell movement; Gene II, aphid transmission; Gene III, DNA binding protein; Gene IV, coat protein; Gene V, reverse transcriptase; Gene VI, translational transactivation of genes I through V. Restriction enzyme sites used for construction of chimeric viruses are shown where applicable. Sequences of CaMV strains W260, D4, and CM1841 are illustrated by stippled, filled-in, and open regions, respectively. 
The systemic cell death symptom is not a consequence of elevated levels of CaMV gene products.

One possible explanation for the systemic necrosis symptom is that the W260 virus replicates to a higher level than the D4 virus. To investigate whether differential levels of virus replication could be associated with the systemic necrosis symptom, we measured virion titers of D4 and W260 in inoculated and upper, noninoculated leaves of $N$. clevelandii. Enzyme-linked immunosorbent assay (ELISA) revealed that the level of D4 virions in both the inoculated and upper, non-
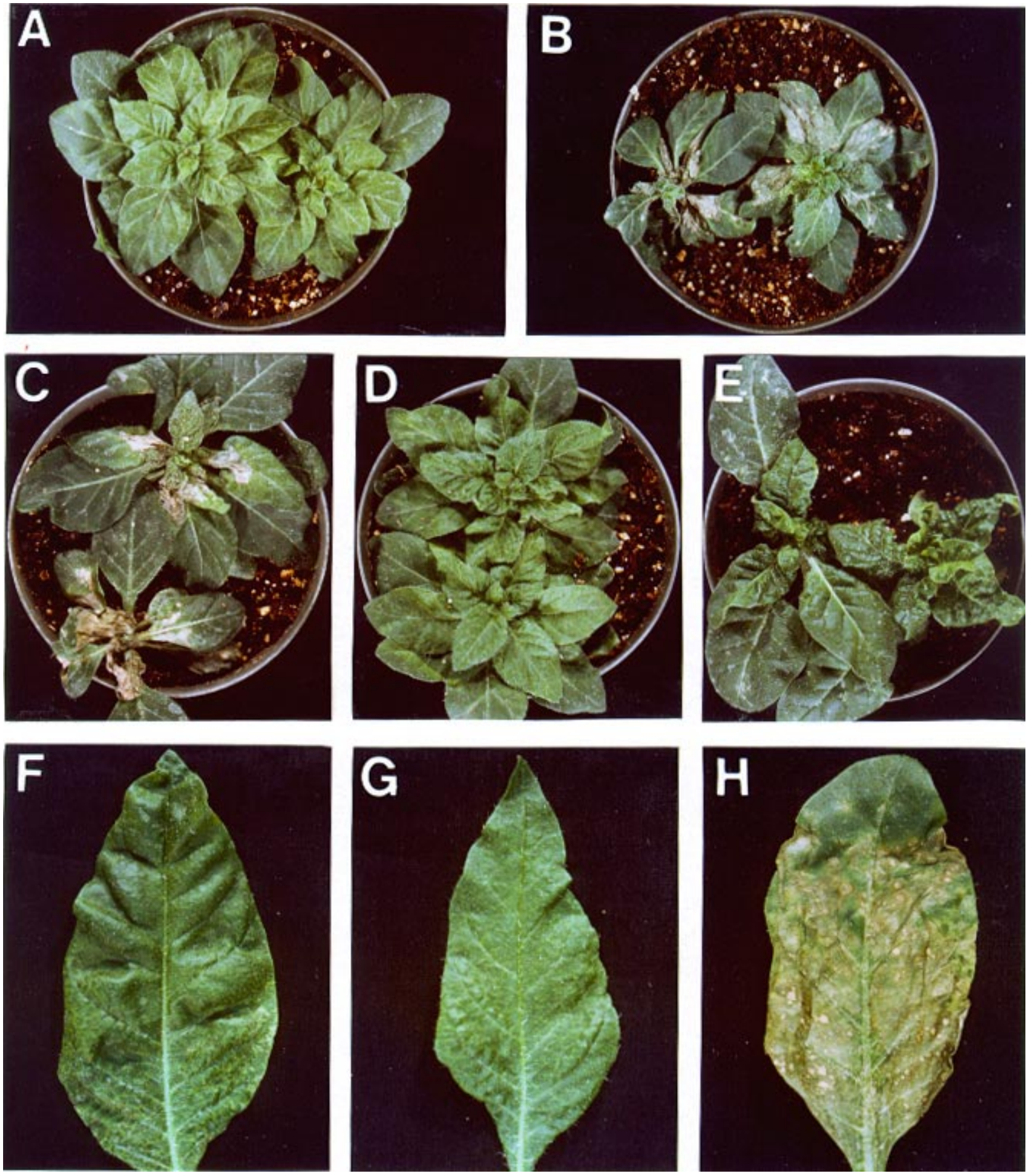

Fig. 2. Systemic symptoms in cauliflower mosaic virus (CaMV)-infected Nicotiana clevelandii and $N$. bigelovii, and their $\mathrm{F}_{1}$ and $\mathrm{F}_{2}$ hybrids. A-D, $N$. clevelandii infected with D4, W260, H191, and H190, respectively. E, N. bigelovii infected with W260. F, Leaf from an $\mathrm{F}_{1}$ hybrid plant $(N$. bigelovii $\times$ $N$. clevelandii) inoculated with W260. $\mathrm{F}_{2}$ progeny infected with W260 showing (G) mosaic symptoms and (H) systemic necrosis. Photos were taken 40 to 45 days after inoculation. 
inoculated $N$. clevelandii leaves was two to three times higher than that of W260 virions (Table 1). We also measured the level of W260 virions in N. bigelovii; this host responds to W260 infection with a systemic mosaic rather than necrosis (Fig. 2E). The W260 titers in both inoculated and upper, noninoculated $N$. bigelovii and $N$. clevelandii leaves were equivalent (Table 1), further evidence that systemic cell death was triggered by a specific interaction between CaMV strain W260 and $N$. clevelandii.

As CaMV gene VI was found to be responsible for triggering systemic cell death, we compared the levels of W260 gene VI protein in $N$. clevelandii leaves that exhibited moderate levels of cell death with the amount in $N$. bigelovii leaves that exhibited only a mosaic symptom. A Western blot (immunoblot) assay showed that the level of W260 gene VI product in $N$. bigelovii leaves was equivalent to or greater than the amount in $N$. clevelandii (Fig. 3). Consequently, it is unlikely that differential levels of virions or gene VI product could be responsible for the systemic necrosis symptom. Instead, the elicitation of systemic necrosis may be determined by the interaction of the W260 gene VI protein with a host factor in $N$. clevelandii.

\section{The HR of $N$. edwardsonii blocks long-distance movement of CaMV rather than local movement in the inoculated leaf.}

The comparison of W260 virion titers in N. clevelandii and $N$. bigelovii revealed that this virus moved unimpeded through $N$. clevelandii as it elicited systemic cell death. In contrast, the HR of $N$. edwardsonii appeared to prevent the systemic movement of W260 (Fig. 1; Schoelz and Shepherd 1988). To compare the reaction of $N$. clevelandii, described in the previ-

Table 1. Comparison of cauliflower mosaic virus particle concentrations in Nicotiana bigelovii and N. clevelandii

\begin{tabular}{|c|c|c|c|c|}
\hline \multirow[b]{2}{*}{ Virus } & \multicolumn{2}{|c|}{ N. bigelovii } & \multicolumn{2}{|c|}{ N. clevelandii } \\
\hline & Inoculated $^{\mathrm{a}}$ & $\begin{array}{c}\text { Upper, } \\
\text { noninoculated }\end{array}$ & Inoculated & $\begin{array}{c}\text { Upper, } \\
\text { noninoculated }\end{array}$ \\
\hline 14 & $6.9 \pm 1.1(2)^{b}$ & $10.8 \pm 4.4(23)$ & $2.7 \pm 0.7(2)$ & $11.3 \pm 4.6(24)$ \\
\hline W260 & $1.6 \pm 0.1(2)$ & $5.7 \pm 3.0(21)$ & $1.1 \pm 0.1$ & $4.2 \pm 2.7(29)$ \\
\hline
\end{tabular}

${ }^{a}$ Micrograms of virions per gram of leaf tissue, as measured by enzymelinked immunosorbent assay.

b Number of plants sampled.

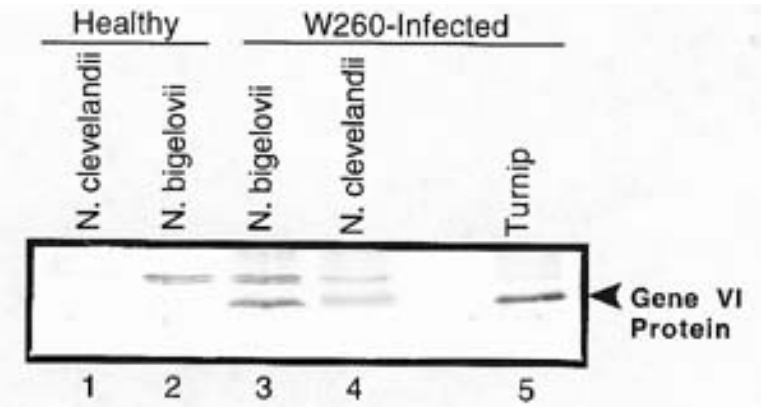

Fig. 3. Comparison of levels of the cauliflower mosaic virus (CaMV) gene VI product in Nicotiana clevelandii and $N$. bigelovii systemically infected with W260 by Western blot (immunoblot) analysis. Equivalent amounts of $N$. bigelovii and $N$. clevelandii samples were loaded in each lane, whereas one tenth of that amount was loaded in the lane containing CaMV-infected turnip tissue. ous section, with the HR of $N$. edwardsonii, we measured the amounts of W260, D4, and selected chimeric viruses in inoculated and upper, noninoculated leaves of $N$. edwardsonii. An ELISA of upper, noninoculated leaves confirmed the visual observations; gene VI of W260 prevented the virus from moving systemically (Table 2). In the inoculated leaves the level of W260 virions was approximately one third of the D4 virion titer (Table 2). This ratio was similar to the W260:D4 virion ratios in inoculated leaves of $N$. clevelandii and $N$. bigelovii (Table 1), even though these plants reacted with systemic cell death and a systemic mosaic, respectively. This comparison indicated that in the inoculated leaf the lower virion titer of W260 relative to D4 was associated with the W260 virus itself, and not due to a specific type of plant reaction against W260. The level of H191 virions was comparable to that of D4 and H190 (Table 2), further evidence that the HR of $N$. edwardsonii did not affect virion concentrations in the inoculated leaves. This study indicated that the HR of $N$. edwardsonii was associated with a block in the long-distance movement of CaMV, but had little effect on local movement in the inoculated leaf.

\section{A single gene in $N$. clevelandii specifies systemic cell death in response to infection by CaMV strain W260.}

To observe the inheritance of the systemic cell death and mosaic traits in $N$. clevelandii and $N$. bigelovii, respectively, crosses were made between these two Nicotiana spp. It was relatively easy to obtain reciprocal hybrids from conventional crosses of $N$. clevelandii and $N$. bigelovii and both the $\mathrm{F}_{1}$ and $\mathrm{F}_{2}$ hybrids were fertile. All $\mathrm{F}_{1}$ plants displayed a systemic mosaic when inoculated with W260, which indicated that systemic cell death behaved as a recessive trait (Table 3, Fig. 2F). The $F_{1}$ plants were selfed and in the $F_{2}$ generation the infected plants revealed a 3:1 segregation for systemic mosaic (Fig. $2 \mathrm{G}$ ) versus necrosis (Fig. $2 \mathrm{H}$ ), showing that a single, nuclear coded gene in $N$. clevelandii determines the systemic cell death trait (Table 3). Furthermore, we observed a 1:1 segregation (necrosis:mosaic) in the progeny that resulted from a backcross of the $\mathrm{F}_{1}$ hybrids to $N$. clevelandii, which confirmed that the systemic cell death trait is conditioned by a single gene (Table 3). This plant gene was designated $c c d 1$, for CaMV cell death gene.

\section{DISCUSSION}

The formation of systemic cell death symptoms in CaMVinfected $N$. clevelandii is caused by an interaction between strain W260 gene VI and a single gene in the host that we have designated ccdl. To identify regions of the W260

Table 2. Comparison of cauliflower mosaic virus particle concentrations in Nicotiana edwardsonii

\begin{tabular}{lccc}
\hline Virus & Host reaction & $\begin{array}{c}\text { Inoculated } \\
\text { leaf }^{\text {a }}\end{array}$ & $\begin{array}{c}\text { Upper, } \\
\text { noninoculated leaf }^{\text {Mosaic }}\end{array}$ \\
\hline D4 & Mosaic & $1.3 \pm 0.2(4)^{\mathrm{b}}$ & $4.0 \pm 1.5(6)$ \\
H190 & Mypersensitive response & $1.1 \pm 0.5(8)$ & $2.1 \pm 0.3(4)$ \\
H191 & Hypersensitive response & $0.4 \pm 0.1(3)$ & $0(4)$ \\
W260 & Hy) & $0(6)$ \\
\hline
\end{tabular}

${ }^{a}$ Micrograms of virions per gram of leaf tissue, as measured by enzyme-

linked immunosorbent assay.

b Number of plants sampled. 
genome that determine systemic cell death in $N$. clevelandii, chimeric viruses were constructed between the wild-type strains W260, D4, and CM1841. Previous research has shown that the source of gene VI in chimeric CaMV strains can determine the ability of the virus to systemically infect solanaceous species (Daubert et al. 1984; Schoelz et al. 1986a). Furthermore, sequences within gene VI specify the development of HR in D. stramonium and N. edwardsonii (Schoelz et al. 1986a; Schoelz and Shepherd 1988). Interestingly, the same region that elicits HR can also elicit systemic cell death in $N$. clevelandii.

The development of systemic cell death did not appear to be due to elevated titers of W260 virions or its gene VI product. CaMV strain D4 virions accumulated to about twice the level of W260 virions in N. clevelandii, and the same difference in virion titer was also evident in N. bigelovii, a host that reacts with a systemic mosaic to both of these viruses. Furthermore, Western blot analysis demonstrated that the level of W260 gene VI expression was equivalent or higher in $N$. bigelovii than in N. clevelandii. Although it is still possible that other CaMV genes may influence development of cell death, our results indicate that $N$. clevelandii recognizes W260 gene VI in a specific manner and that this recognition event triggers systemic cell death.

To identify the host gene that interacts with gene VI of CaMV for elicitation of systemic cell death, we made crosses between $N$. clevelandii and $N$. bigelovii. The progeny of this interspecific cross are fertile; the two species have the same chromosome number $(n=24)$ and are considered closely related to each other (Goodspeed 1954). In our crosses, all $F_{1}$ plants displayed a systemic mosaic when inoculated with W260. In the $\mathrm{F}_{2}$ generation, infected plants revealed a 3:1 segregation for systemic mosaic versus necrosis. This analysis indicated that a single, recessive, nuclear coded gene in $N$. clevelandii was responsible for the systemic cell death trait. However, it is also possible that $N$. bigelovii might contain a dominant allele that suppresses cell death triggered by CaMV strain W260.

There are few examples in which a specific viral symptom has been shown to be conditioned by an interaction between a single plant gene and a single viral gene. In contrast, gene-forgene relationships have been well established for host resistance to viral infection. For example, it has been shown that the viral replicase proteins of TMV interact with the $N$ resistance gene in tobacco (Padgett and Beachy 1993; Padgett et al. 1997; Witham et al. 1994) and with the Tml resistance gene in tomato (Meshi et al. 1988). Furthermore, the TMV movement protein elicits resistance in $\operatorname{Tm} 2$ tomato (Meshi et al. 1989), and the TMV coat protein elicits resistance in $N^{\prime}$ tobacco (Knorr and Dawson 1988; Culver and Dawson 1989). In potato, the potato virus $\mathrm{X}(\mathrm{PVX})$ coat protein interacts with both the $N x$ and $R x$ resistance genes of potato (Kavanagh et al. 1992), whereas the PVX movement protein elicits HR in potato varieties that have the $N b$ resistance gene (Malcuit et al. 1999). Resistance to CaMV in several Arabidopsis ecotypes has been shown to be conditioned by single genes (Leisner et al. 1993; Callaway et al. 1996), and in one case CaMV gene VI is responsible for overcoming resistance in this host (Agama et al. 1998).

One of the few studies that deals with plant genes influencing virus symptomatology identified host and virus genes that determine severe local chlorosis in tobacco (N. tabacum, cv. Ky57) inoculated with CMV strain Y (Takahashi and Ehara 1993). It was shown that severe local chlorosis in CMV(Y)-inoculated Ky57 tobacco is induced by an interaction of two recessive host genes and the virus coat protein gene. Furthermore, these two recessive host genes completely cosegregated with two recessive loci ( $y b 1$ and $y b 2$ genes) of Ky57 that are known to be responsible for chlorophyll reduction in the stem (Henika 1932). A second study has shown that an incompletely dominant gene in $N$. bigelovii conditions a yellow mosaic symptom in response to infection with satellite Y RNA of CMV (Masuta et al. 1993).

In the present study, the monogenic systemic cell death trait revealed in W260-infected $N$. clevelandii was not linked to any visible phenotype in the uninoculated host. Therefore, at this point one can only speculate on the function of the systemic cell death gene and on the way it interacts with the gene VI product of the invading virus. For instance, the systemic cell death gene might be a defective copy of a cellular protectant (antioxidant) gene such as glutathione-S-transferase or glutathione peroxidase. Products of such genes are believed to block plant cell and tissue necrosis (Levine et al. 1994; Tenhaken et al. 1995). More likely, this recessive $N$. clevelandii gene could be a positive regulator of cellular protectant gene expression, which fails to carry out its function during systemic viral infection, enabling necrosis to develop. The same or a similar defective regulator gene might be responsible for the development of spontaneous necrosis in $N$. clevelandii plants that express a fenthion-sensitivity gene from tomato (Rommens et al. 1995). In fact, a positive regulator of cellular protectants has been identified in the weed Conyza bonariensis as a single gene with Mendelian inheritance (Shaaltiel et al. 1988). Also, several monogenic, recessive mutants exist in Arabidopsis that are unable to control the spread of necrosis during pathogenesis and aging (Greenberg et al. 1994). One of these mutants shows more severe, aging-related necrosis

Table 3. Segregation of systemic necrosis and mosaic in crosses of Nicotiana clevelandii $(\mathrm{Nc})$ and $\mathrm{N}$. bigelovii $(\mathrm{Nb})$ after inoculation with cauliflower mosaic virus strain W260

\begin{tabular}{|c|c|c|c|c|c|}
\hline Host & Systemic mosaic & Systemic necrosis & Observed ratio $^{a}$ & Expected ratio $^{\mathrm{a}}$ & $\chi^{2}$ \\
\hline$N c$ & 0 & 45 & $0: 45$ & & \\
\hline $\mathrm{Nb}$ & 52 & 0 & $52: 0$ & & \\
\hline $\mathrm{F}_{1}\left[N c\right.$ ㅇ $\left.\times N b b^{\lambda}\right]$ & 195 & 0 & $195: 0$ & & \\
\hline 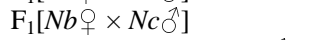 & 32 & 0 & $32: 0$ & & \\
\hline $\mathrm{F}_{2}\left[\right.$ selfed $\mathrm{F}_{1}(N c$ ㅇ $\left.\times N b \overbrace{}^{\lambda})\right]$ & 133 & 41 & $3.2: 1$ & $3: 1$ & 0.122 \\
\hline $\mathrm{F}_{2}\left[\right.$ selfed $\left.\mathrm{F}_{1}\left(N b \propto \times N c \delta^{\lambda}\right)\right]$ & 22 & 6 & $3.6: 1$ & $3: 1$ & 0.322 \\
\hline $\mathrm{F}_{1}\left[N c+\times N b^{\lambda}\right] \times N c$ & 18 & 24 & $0.75: 1$ & $1: 1$ & 0.881 \\
\hline
\end{tabular}

${ }^{a}$ Systemic mosaic : systemic necrosis. 
under low light intensity (Dietrich et al. 1994), the same light-dependent response observed during CaMV-elicited systemic necrosis in $N$. clevelandii.

Alternatively, the recessive $N$. clevelandii gene that interacts with the CaMV gene VI product during systemic cell death could potentially code for a plant protein that is part of the host translation machinery. One or more of these proteins must interact with the gene VI product to facilitate the translational transactivation of genes I through $\mathrm{V}$ during viral pathogenesis (Bonneville et al. 1989; Gowda et al. 1989). The copy of such a protein present in $N$. clevelandii might interact with CaMV gene VI in a manner that alters translational transactivation and triggers host responses that result in the development of systemic cell death. However, the relationship between translational transactivation, the molecular function assigned to gene VI, and the ability of gene VI to elicit systemic cell death or HR remains unclear.

\section{MATERIALS AND METHODS}

\section{CaMV wild-type strains and construction of chimeric viruses.}

The wild-type CaMV strains W260 and D4 have been described previously (Gracia and Shepherd 1985; Schoelz et al. 1986 b). Both viruses have been cloned in infectious form into the SalI site of the plasmid vector pBR322 to form pCaMVW260 and pCaMVD4, respectively (Schoelz et al. 1986b; Schoelz and Shepherd 1988). The chimeric virus clones pH190 and pH191 were made by exchanging SalI$B s t$ EII restriction enzyme-generated DNA fragments between pCaMVW260 and pCaMVD4. The construction of chimeric viruses $\mathrm{H} 7$ and $\mathrm{H} 35$ has been described previously (Daubert et al. 1984; Schoelz and Shepherd 1988).

Infections with cloned viral DNA were initiated by inoculating turnips (Brassica rapa cv. Just Right) with viral DNA excised from the plasmid vector with the appropriate restriction enzyme as previously described (Howell et al. 1980; Lebeurier et al. 1980). Viral DNA was purified from infected plants following the procedure of Gardner and Shepherd (1980) and identification of chimeric viruses was confirmed by mapping key restriction enzyme sites. Wild-type and chimeric viruses were stored in lyophilized turnip leaf tissue at $4^{\circ} \mathrm{C}$ to serve as inoculum for experiments.

\section{Analysis of host symptoms and virus detection.}

Virus inoculum was prepared from infected turnips as described by Schoelz et al. (1986a) or as purified virions (Hull et al. 1976). Reciprocal hybrids of $N$. bigelovii and $N$. clevelandii were obtained from conventional crosses. All Nicotiana spp. and hybrids were inoculated 5 to 6 weeks after seeds were sown. In the case of $N$. clevelandii and the $\mathrm{F}_{1}$ and $\mathrm{F}_{2}$ hybrids, seeds were soaked in $2.0 \% \mathrm{NaOCl}$ for 15 to $20 \mathrm{~min}$ prior to sowing, as described by Burk (1957), to overcome dormancy. Inoculated plants were maintained for 45 to 50 days either in growth chambers set for a 10-h day with a light intensity of 100 to $180 \mu \mathrm{E} \mathrm{s}^{-1} \mathrm{~m}^{-2}$ at $18^{\circ} \mathrm{C}$ or in the greenhouse during the months of October through April. Symptoms were recorded daily. The presence of CaMV virions in leaves showing systemic symptoms was verified by ELISA (Clark and Adams 1977) as described previously (Anderson et al. 1991).

\section{SDS-polyacrylamide gel electrophoresis} and Western blot analysis of CaMV gene VI protein.

Samples were prepared by grinding infected tissue with a mortar and pestle at a 1:5 (wt/vol) dilution in $0.02 \mathrm{M}$ potassium phosphate buffer $(\mathrm{pH} 7.0)$. The homogenate was centrifuged for $30 \mathrm{~s}$ at $12,000 \times g$. To $200 \mu \mathrm{l}$ of the clarified extract, an equal volume of $2 \times$ sodium dodecyl sulfate (SDS) treatment buffer (0.125 M Tris [pH 6.8], 4\% [wt/vol] SDS, 20\% [vol/vol] glycerol, and $10 \%$ [vol/vol] 2-mercaptoethanol) was added. The samples were heated for $4 \mathrm{~min}$ at $100^{\circ} \mathrm{C}$, then reduced and alkylated (Lane 1978). The equivalent of $2 \mathrm{mg}$ of tissue was then loaded into a well for the respective sample of a $10 \%$ acrylamide mini-gel (Laemmli 1970). Gels were stained with Coomassie blue R-250 to confirm that equal amounts of protein were loaded or they were transferred to nitrocellulose membranes for Western analysis.

Proteins were transferred to nitrocellulose membranes for $1.5 \mathrm{~h}$ at $300 \mathrm{~mA}$ (constant current) (Towbin et al. 1979) and blocked overnight in blocking buffer (phosphate buffered saline [PBS; pH 7.4], 5\% [wt/vol] nonfat dry milk, $1 \%$ [wt/vol] bovine serum albumin [BSA], $0.01 \%$ [vol/vol] Antifoam A). Membranes were incubated at room temperature for $1.5 \mathrm{~h}$ with a 1:500 dilution of anti-CaMV gene VI IgG (in PBS Tween buffer [pH 7.4] containing $2.0 \mathrm{~g}$ of BSA per liter as the blocking agent), followed by an incubation for $1.5 \mathrm{~h}$ at room temperature with a 1:7,500 dilution of alkaline phosphataselabeled goat-anti-rabbit IgG (Fisher, St. Louis, MO). Between each step the membranes were washed with PBS ( $\mathrm{pH} 7.4)$, $0.05 \%$ Tween 20 . Protein bands were visualized by addition of $10 \mathrm{ml}$ of alkaline phosphatase color developer (100 mM Tris [pH 9.1], $100 \mathrm{mM} \mathrm{NaCl}, 5 \mathrm{mM} \mathrm{MgCl}_{2}, 0.4 \mathrm{mM}$ nitro blue tetrazolium chloride, $0.4 \mathrm{mM}$ 5-bromo-4-chloro-3-indolyl phosphate D-toluidine salt, which was allowed to react for 10 to $20 \mathrm{~min}$.

\section{ACKNOWLEDGMENTS}

This research was supported by a grant from the Food for the 21st Century program at the University of Missouri and by U.S. Department of Agriculture/National Research Initiative Competitive Grant No. 9835303-6711. This is a contribution from the Missouri Agricultural Experiment Station, Journal Series No. 12,922.

\section{LITERATURE CITED}

Agama, K., Anderson, E., Beach, S., Schoelz, J., and Leisner, S. M. 1998. CaMV gene VI controls resistance-breakage in Arabidopsis thaliana ecotype Tsu-0. Phytopathology 88:S2.

Anderson, E. J., Qiu, S. G., and Schoelz, J. E. 1991. Genetic analysis of determinants of disease severity and virus concentration in cauliflower mosaic virus. Virology 181:647-655.

Bonneville, J. M., Sanfaçon, H., Fütterer, J., and Hohn, T. 1989. Posttranscriptional trans-activation in cauliflower mosaic virus. Cell 59: 1135-1143.

Burk, L. G. 1957. Overcoming seed dormancy in Nicotiana. Agronomy J. 49:461.

Callaway, A., Liu, W., Andrianov, V., Stenzler, L., Zhao, J., Wettlaufer, S., Jayakumar, P., and Howell, S. H. 1996. Characterization of cauliflower mosaic virus (CaMV) resistance in virus-resistant ecotypes of Arabidopsis. Mol. Plant-Microbe Interact. 9:810-818.

Clark, M. F., and Adams, A. N. 1977. Characteristics of the microplate method of enzyme-linked immunosorbent assay for the detection of plant viruses. J. Gen. Virol. 34:475-483.

Culver, J. N., and Dawson, W. O. 1989. Point mutations in the coat protein gene of tobacco mosaic virus induce hypersensitivity in Nico- 
tiana sylvestris. Mol. Plant-Microbe Interact. 2:209-213.

Culver, J. N., Lindbeck, A. G. C., and Dawson, W. O. 1991. Virus-host interactions: Induction of chlorotic and necrotic responses in plants by tobamoviruses. Annu. Rev. Phytopathol. 29:193-217.

Daubert, S. 1988. Sequence determinants of symptoms in the genomes of plant viruses, viroids, and satellites. Mol. Plant-Microbe Interact. 1:317-325.

Daubert, S., J. Schoelz, L. Debao, and Shepherd, R. J. 1984. Expression of disease symptoms in cauliflower mosaic virus genomic hybrids. J. Mol. Appl. Genet. 2:537-547.

Dawson, W. O., and Hilf, M. E. 1992. Host-range determinants of plant viruses. Annu. Rev. Plant Physiol. Plant Mol. Biol. 43:527-555.

Dietrich, R. A., Delaney, T. P., Uknes, S. J., Ward, E. R., Ryals, J. A., and Dangl, J. L. 1994. Arabidopsis mutants simulating disease resistance response. Cell 77:565-577.

Dijkstra, J., Bruin, G. C. A., Burgers, A. C., Van Loon, L. C., Ritter, C., Van de Sanden, P. A. C. M., and Wieringa-Brants, D. H. 1977. Systemic infection of some N-gene carrying Nicotiana species and cultivars after inoculation with tobacco mosaic virus. Neth. J. Plant Pathol. 83:41-59.

Gardner, R. C., and Shepherd, R. J. 1980. A procedure for rapid isolation and analysis of cauliflower mosaic virus DNA. Virology 106:159-161.

Geri, C., Cecchini, E., Giannakou, M. E., Covey, S. N., and Milner, J. J. 1999. Altered patterns of gene expression in Arabidopsis elicited by cauliflower mosaic virus (CaMV) infection and by a CaMV gene VI transgene. Mol. Plant-Microbe Interact. 12:377-384.

Goodspeed, T. H. 1954. The Genus Nicotiana. Chronica Botanica, Waltham, MA.

Gowda, S., Wu, F. C., Scholthof, H. B., and Shepherd, R. J. 1989. Gene VI of figwort mosaic virus (Caulimovirus group) functions in posttranscriptional expression of genes on the full-length RNA transcript. Proc. Natl. Acad. Sci. USA 86:9203-9207.

Gracia, O., and Shepherd R. J. 1985. Cauliflower mosaic virus in the nucleus of Nicotiana. Virology 146:141-145.

Greenberg, J. T., Guo, A., Klessig, D. F., and Ausubel, F. M. 1994. Programmed cell death in plants: A pathogen-triggered response activated coordinately with multiple defense functions. Cell 77:551-563.

Henika, F. S. 1932. The inheritance of the white burley character in tobacco. J. Agric. Res. 44:477-493.

Howell, S. H., Walker, L. L., and Dudley, R. K. 1980. Cloned cauliflower mosaic virus DNA infects turnips (Brassica rapa). Science 208:1255-1267.

Hull, R., Shepherd, R. J., and Harvey, J. D. 1976. Cauliflower mosaic virus: An improved purification procedure and some properties of the virus particles. J. Gen. Virol. 31:93-100.

Kavanagh, T., Goulden, M., Santa Cruz, S., Chapman, S., Barker, I., and Baulcombe, D. C. 1992. Molecular analysis of a resistance-breaking strain of potato virus X. Virology 189:609-617.

Knorr, D. A., and Dawson, W. O. 1988. A point mutation in the tobacco mosaic capsid protein gene induces hypersensitivity in Nicotiana sylvestris. Proc. Natl. Acad. Sci. USA 85:170-174.

Laemmli, U. K. 1970. Cleavage of structural proteins during the assembly of head of bacteriophage T4. Nature 227:680-685.

Lane, L. C. 1978. A simple method for stabilizing protein-sulfhydryl groups during SDS-gel electrophoresis. Anal. Biochem. 86:655-664.

Lebeurier, G. L., Hirth, L., Hohn, B., and Hohn, T. 1980. Infectivities of native and cloned DNA of cauliflower mosaic virus. Gene 12:139-146.

Leisner, S. M., Turgeon, R., and Howell, S. H. 1993. Effects of host plant development and genetic determinants on the long-distance movement of cauliflower mosaic virus in Arabidopsis. Plant Cell 5: 191-202.

Levine, A., Tenhaken, R., Dixon, R., and Lamb. C. 1994. $\mathrm{H}_{2} \mathrm{O}_{2}$ from the oxidative burst orchestrates the plant hypersensitive response. Cell
79:583-593.

Malcuit, I., Marano, M. R., Kavanagh, T. A., De Jong, W., Forsyth, A., and Baulcombe, D. C. 1999. The 25-kDa movement protein of PVX elicits $\mathrm{Nb}$-mediated hypersensitive cell death in potato. Mol. PlantMicrobe Interact. 12:536-543.

Masuta, C., Suzuki, M., Kuwata, S., Takanami, Y., and Koiwai, A. 1993. Yellow mosaic symptoms induced by $\mathrm{Y}$ satellite RNA of cucumber mosaic virus is regulated by a single incompletely dominant gene in wild Nicotiana species. Phytopathology 83:411-413.

Meshi, T., Motoyoshi, F., Adachi, A., Watanabe, Y., Takamatsu, N., and Okada, Y. 1988. Two concomitant base substitutions in the putative replicase genes of tobacco mosaic virus confer the ability to overcome the effects of a tomato resistance gene, Tm-1. EMBO J. 7:1575-1581.

Meshi, T., Motoyoshi, F., Maeda, T., Yoshiwoka, S. Watanabe, H., and Okada, Y. 1989. Mutations in the tobacco mosaic virus $30-\mathrm{kD}$ protein gene overcome Tm-2 resistance in tomato. Plant Cell 1:515-522.

Padgett, H. S., and Beachy, R. N. 1993. Analysis of a tobacco mosaic virus strain capable of overcoming $N$ gene-mediated resistance. Plant Cell 5:577-586.

Padgett, H. S., Watanabe, Y., and Beachy, R. N. 1997. Identification of the TMV replicase sequence that activates the $N$ gene-mediated hypersensitive response. Mol. Plant-Microbe Interact. 10:709-715.

Rommens, C. M. T., Salmeron, J. M., Baulcombe, D. C., and Staskawicz, B. J. 1995. Use of a gene expression system based on potato virus $\mathrm{X}$ to rapidly identify and characterize a tomato Pto homolog that controls fenthion sensitivity. Plant Cell 7:249-257.

Schoelz, J. E., and Shepherd, R. J. 1988. Host range control of cauliflower mosaic virus. Virology 162:30-37.

Schoelz, J. E., Shepherd, R. J., and Daubert, S. D. 1986a. Region VI of cauliflower mosaic virus encodes a host range determinant. Mol. Cell. Biol. 6:2632-2637.

Schoelz, J. E., Shepherd, R. J., and Richins, R. D. 1986b. Properties of an unusual strain of cauliflower mosaic virus. Phytopathology 76:451454

Scholthof, H. B., Scholthof, K.-B. G., and Jackson, A. O. 1995. Identification of tomato bushy stunt virus host-specific symptom determinants by expression of individual genes from a potato virus $\mathrm{X}$ vector. Plant Cell 7:1157-1172.

Shaaltiel, Y., Chua, N.-H., Gepstein, S., and Gressel, J. C. 1988. Dominant pleiotropy controls enzymes co-segregating with paraquat resistance in Conyza bonariensis. Theor. Appl. Genet. 75:850-856.

Stratford, R., and Covey, S.N. 1989. Segregation of cauliflower mosaic virus symptom genetic determinants. Virology 172:451-459.

Takahashi, H., and Ehara, Y. 1993. Severe chlorotic spot symptoms in cucumber mosaic virus strain Y-infected tobaccos are induced by a combination of the virus coat protein gene and two host recessive genes. Mol. Plant-Microbe Interact. 6:182-189.

Taliansky, M. E., Ryabov, E. V., Robinson, D. J., and Palukaitis, P. 1998. Tomato cell death mediated by complementary plant viral satellite RNA sequences. Mol. Plant-Microbe Interact. 11:1214-1222.

Tenhaken, R., Levine, A., Brisson, L. F., Dixon, R., and Lamb, C. 1995. Function of the oxidative burst in hypersensitive disease resistance. Proc. Natl. Acad. Sci. USA 92:4158-4163.

Towbin, H., Staehlin, T., and Gordon, J. 1979. Electrophoretic transfer of proteins from polyacrylamide gels to nitrocellulose sheets: Procedure and some applications. Proc. Natl. Acad. Sci. USA 76:43504354.

Wang, D. W., and Maule, A. J. 1995. Inhibition of gene expression associated with plant virus replication. Science 267:229-231.

Whitham, S., Dinesh-Kumar, S. P., Cho, D., Hehl, R., Corr, C., and Baker, B. 1994. The product of the tobacco mosaic virus resistance gene $N$ : Similarity to Toll and the Interleukin-1 receptor. Cell 78: 1101-1115. 